NHŨ̃NG THÁCH THỬC ĐặT RA CHO CÁC DOANH NGHIỆP NHỎ VÀ VỪA VIỆT NAM

\title{
CHALLENGES THAT VIETNAMESE SMES HAVE BEEN FACING
}

\author{
Vương Đức Hoàng Quân \\ Viện Nghiên cứu Phát triển Tp. Hồ Chí Minh \\ (Bài nhận ngày 7 tháng 8 năm 2014, hoàn chỉnh sưa chũa ngày 21 tháng 8 năm 2014)
}

\section{TÓM TẮT}

Kinh tế Việt Nam đang đối mặt với nhũng co hội và thách thức của cơ chế thị trường và toàn cầu hóa. Chính sách phát triển kinh tế - xã hộ đã mang lại một số kết quả tích cực; nhu churong trình chuyển dịch cơ cấu kinh tế trong thời gian qua đã góp phần vào việc thúc đẩy tăng truởng kinh tế, thay đổi tỷ trọng giũa các ngành. Song song đó, tiến trình hội nhập và sụ tham gia ngày càng sâu rộng của Việt Nam vào các tổ chức, diê̂n dàn quốc tế, đòi hỏi tù̀ng doanh nghiệp cần phải có chiến lược phù hợp để thích nghi với môi truờng kinh doanh mới, đáp ứng nhũng đòi hỏi của canh tranh.

Ra đời tù̀ sụ thay đổi về tu duy kinh tế sau chính sách Đổi mới năm 1986, doanh nghiệp nhỏ và vìa $(D N N V V)$ hiện là quy mô doanh nghiệp chiếm đa số, và là bộ phận quan trọng tạo ra tổng sản phẩm quốc nội (GDP). Sự thay đổi và vận động không ngùng của nền kinh tế đã tạo nhiều điều kiện DNNVV mở rộng sản xuất và phát triển kinh doanh, đồng thời cũng mang đến không it khó khăn thư thách. Do đó, đầu tu đổi mới là cần thiết cho sự tồn tại và phát triển của DNNVV.

Nội dung bài viết tập trung nghiên cứu các vấn đề mà DNNVV đang phải đối mặt đồng thời nhận diện vấn đề cốt lõi nhất mà doanh nghiệp đang gặp phải. Do khó khăn về mặt số liệu, nghiên cứu sẽ chỉ sủ dụng số liệu của các doanh nghiệp nhỏ và vùa của thành phố Hồ Chí Minh để thưc hiện việc phân tích. Điều này không làm ảnh huởng nhiều đến kết quả nghiên cứu vì thành phố Hồ Chí Minh là địa phuoong có nền kinh tế phát triển, đóng góp vào GDP cao nhất cả nước và số lượng doanh nghiệp cũng nhiều nhất cả nước. Cuối cùng, một số giải pháp sẽ đuợc đề xuất nhằm giúp DNNVV vuợt qua khó khăn để phát triển bền vũng, góp phần vào sư tăng trưởng chung của nền kinh tế.

Tù khóa: DNNVV, thục trạng, thách thức, khuyến nghị.

\begin{abstract}
Vietnam economy is facing both opportunities and challenges of the market mechanism and globalization. Social and economic development policies have created positive outcomes. For instance, the economic structural change program has brought out promising results in improving the economic growth and contributing to a more proportionate structure of the industries. At the same time, the progress of integration and participation of Vietnam to international organizations and forums required business enterprises to have appropriate policies in order to adapt to the new business environment and meet the requirements of competition.
\end{abstract}


Small and Medium Enterprises (SMEs), which are often considered as the direct result of the changes in economic thought after Renewal policy (Doi Moi) in 1986, is now playing an important part in the economy in terms of the quantity of enterprises as well as the contribution to the country's GDP. Changes and continuous movements of the economy supported SMEs to expand and develop but brought into many difficulties and challenges. Therefore, the internal renewal is essential to the survival and development of SMEs themselves.

The paper aims at identifying the challenges that SMEs have been facing and the root of those issues. Due to the difficulties in collecting data, the research limits primarily with the analysis on the data from the SMEs in Ho Chi Minh City. However, this limitation had a small impact on the research result as Ho Chi Minh City is the most developed city and has the highest contribution to GDP and the highest number of business enterprises. Finally, the research had provided a number of suggestions which may help SMEs overcome difficulties to develop sustainably and contribute more positively to the overall development of the economy.

Key words: SME, fact, challenge, recommendation

\section{TỔNG QUAN VỀ DNNVV}

Đầu tiên, chính ta cần hiểu rõ về khái niệm của DNNVV. Hiện nay chưa có một định nghĩa chung về DNNVV. Trên thế giới, tùy thuộc vào loại hình doanh nghiệp, đặc điểm kinh tế - kỹ thuật, trình độ phát triển của vùng lãnh thổ, mặt bằng giá trị sức lao động, trị giá tài sản, thiết bị hay mục đích xếp loại doanh nghiệp trong từng thời kỳ nhất định mà các nước có những tiêu chí khác nhau để xác định DNNVV. Do đó, việc xác định DNNVV này chỉ mang tính chất tương đối. Trong đó, hai tiêu chí được sử dụng phổ biến nhất là quy mô vốn và số lượng lao động. Phù hợp với từng giai đoạn phát triển, mà độ lớn của các chỉ tiêu này cũng khác nhau. Ta có thể đưa ra một ví dụ minh họa cụ thể với hệ thống tiêu chí phân loại DNNVV của tổ chức Ngân hàng thế giới như sau:

Bảng 1: Tiêu chíxác định DNNVV của Ngân hàng thế giới

\begin{tabular}{|c|l|c|c|c|}
\hline STT & \multicolumn{1}{|c|}{ Phân loại } & $\begin{array}{c}\text { Số lao động } \\
\text { (Người) }\end{array}$ & $\begin{array}{c}\text { Số vốn } \\
\text { (USD) }\end{array}$ & $\begin{array}{c}\text { Doanh thu } \\
\text { (USD) }\end{array}$ \\
\hline 1 & DN cực nhỏ & 10 & $<100.000$ & $<100.000$ \\
\hline 2 & DN nhỏ & $<50$ & $<3.000 .000$ & $<3.000 .000$ \\
\hline 3 & DN vừa & $<300$ & $<15.000 .000$ & $<15.000 .000$ \\
\hline
\end{tabular}

Nguồn: Ngân hàng thế giới.

Tại Việt Nam, Theo Nghị định 56/2009/NĐ$\mathrm{CP}$ của Chính phủ ngày 30 tháng 9 năm 2009 về trợ giúp phát triển doanh nghiệp nhỏ và vừa, doanh nghiệp nhỏ và vừa là cơ sở kinh doanh đã đăng ký kinh doanh theo quy định pháp luật, được chia thành ba cấp: siêu nhỏ, nhỏ, vừa theo quy mô tổng nguồn vốn (tổng nguồn vốn tương đương tổng tài sản được xác định trong bảng cân đối kế toán của doanh nghiệp) hoặc số lao động bình quân năm (tổng nguồn vốn là tiêu chí ưu tiên), cụ thể: 
Bảng 2: Tiêu chíxác định DNNVV tại Việt Nam

\begin{tabular}{|c|c|c|c|c|c|}
\hline \multirow{2}{*}{$\begin{array}{l}\text { Quy mô } \\
\text { Khu vực }\end{array}$} & \multirow{2}{*}{$\begin{array}{c}\begin{array}{c}\text { Doanh nghiệp } \\
\text { siêu nhỏ }\end{array} \\
\text { Số lao động }\end{array}$} & \multicolumn{2}{|c|}{ Doanh nghiệp nhỏ } & \multicolumn{2}{|c|}{ Doanh nghiệp vừa } \\
\hline & & $\begin{array}{c}\text { Tổng } \\
\text { nguồn vốn }\end{array}$ & $\begin{array}{l}\text { Số lao } \\
\text { động }\end{array}$ & $\begin{array}{c}\text { Tổng } \\
\text { nguồn vốn }\end{array}$ & $\begin{array}{c}\text { Số lao } \\
\text { động }\end{array}$ \\
\hline I. Nông, lâm nghiệp và thủy sản & $\begin{array}{c}10 \text { người trở } \\
\text { xuống }\end{array}$ & $\begin{array}{l}20 \text { tỷ đồng } \\
\text { trở xuống }\end{array}$ & $\begin{array}{c}\text { từ trên } \\
10 \text { - } 200 \\
\text { người }\end{array}$ & $\begin{array}{l}\text { từ trên } \\
20-100 \text { tỷ } \\
\text { đồng }\end{array}$ & $\begin{array}{c}\text { từ trên } \\
200 \text { - } 300 \\
\text { người }\end{array}$ \\
\hline II. Công nghiệp và xây dựng & $\begin{array}{l}10 \text { người trở } \\
\text { xuống }\end{array}$ & $\begin{array}{l}20 \text { tỷ đồng } \\
\text { trở xuống }\end{array}$ & $\begin{array}{c}\text { từ trên } \\
10 \text { - } 200 \\
\text { người }\end{array}$ & $\begin{array}{c}\text { từ trên } \\
20-100 \text { tỷ } \\
\text { đồng }\end{array}$ & $\begin{array}{c}\text { từ trên } \\
200 \text { - } 300 \\
\text { người }\end{array}$ \\
\hline III. Thương mại và dịch vụ & $\begin{array}{l}10 \text { người trở } \\
\text { xuống }\end{array}$ & $\begin{array}{l}10 \text { tỷ đồng } \\
\text { trở xuống }\end{array}$ & $\begin{array}{l}\text { từ trên } \\
10-50 \\
\text { người }\end{array}$ & $\begin{array}{l}\text { từ trên } \\
10 \text { - } 50 \text { tỷ } \\
\text { đồng }\end{array}$ & $\begin{array}{c}\text { từ trên } \\
50 \text { - } 100 \\
\text { người }\end{array}$ \\
\hline
\end{tabular}

Nguồn: Nghị định 56/2009/NĐ-CP.

\section{VAI TRÒ CỦA DNNVV TRONG NỀN KINH TẾ}

DNNVV có vị trí hết sức đặc biệt trong nền kinh tế các nước, kể cả đối với các quốc gia có trình độ phát triển cao. Nhất là trong giai đoạn hội nhập như hiện nay, vai trò của DNNVV lại càng quan trọng, thể hiện ở một số nét cơ bản như sau:

- DNNVV cung cấp một lượng hàng hóa dịch vụ đáng kể cho nền kinh tế. Bởi lẽ, DNNVV chiếm đa số về mặt số lượng trong tổng số cơ sở sản xuất và kinh doanh hiện nay. Số liệu minh họa cho vấn đề này sẽ được trình bày trong phần thực trạng phát triển dưới đây. Đồng thời, tốc độ gia tăng của quy mô doanh nghiệp này nhanh hơn so với các doanh nghiệp lớn. Bên cạnh đó, DNNVV có góp phần quan trọng vào sự gia tăng tổng sản phẩm quốc nội (GDP). Theo Tổng thư ký Hiệp hội DNNVV Việt Nam, thì hiện nay DNNVV đóng góp gần 45\% GDP của cả nước [1].

- DNNVV tạo ra việc làm và thu nhập cho người lao động. Thực tế những năm qua cho thấy các DNNVV là nguồn tạo việc làm cho tất cả các ngành, nhất là đối với nguồn lao động chưa qua đào tạo. Theo Hiệp hội DNNVV Việt Nam, khối loại hình doanh nghiệp này tạo ra hơn 1 triệu việc làm mỗi năm [1]. Từ đó, chúng ta có thể thấy DNNVV đã góp phần đáp ứng nhu cầu việc làm, nâng cao mức sống người dân, và giải quyết các vấn đề an sinh xã hội.

- DNNVV thu hút vốn đầu tư cho nền kinh tế, đồng thời khai thác và phát huy tốt các nguồn lực tại chỗ. Sự ra đời và phát triển của DNNVV trong giai đoạn hiện nay chính là động lực thúc đẩy sự tăng trưởng của nền kinh tế. Quy mô doanh nghiệp này xuất hiện ở tất cả các hình thức: doanh nghiệp nhà nước, doanh nghiệp tư nhân, công ty cổ phần, doanh nghiệp có vốn đầu tư nước ngoài. Qua đó cho thấy sự tham gia đầu tư của mọi đối tượng, mọi thành phần kinh tế. Mặt khác, DNNVV có mặt ở hầu hết các vùng, các địa phương, vì vậy có điều kiện tận dụng các nguồn lực tại chỗ, khai thác tiềm năng thế mạnh 
của từng vùng. Bùi Thị Thu Hà [1] chỉ ra rằng, DNNVV đã sử dụng khoảng 49\% lực lượng sản xuất phi nông nghiệp trong cả nước, tại một số vùng DNNVV đã sử dụng gần như tất cả lực lượng lao động phi nông nghiệp.

- DNNVV góp phần vào sự năng động của nền kinh tế. DNNVV phải thường xuyên thay đổi để thích nghi với môi trường kinh doanh; do đó sự ra đời, phát triển hoặc phá sản của DNNVV luôn tuân theo những quy luật thị trường. Bên cạnh đó, xuất phát từ chính đặc điểm nhỏ về quy mô vốn và lao động, DNNVV có tính linh hoạt cao trong hoạt động sản xuất kinh doanh, dễ chuyển đổi mặt hàng, góp phần vào làm nền kinh tế năng động hơn. Ngoài ra, do chịu nhiều sức ép lớn từ nền kinh tế, nhà quản lý DNNVV phải là những người đi đầu trong đổi mới, đưa ra những chuyển đổi phù hợp với môi trường kinh doanh. Sự có mặt của đội ngũ này sẽ tạo ra một cơ cấu kinh tế năng động, linh hoạt phù hợp với thị trường.

Tóm lại, DNNVV có một vai trò hết sức quan trọng trong bất kỳ nền kinh tế nào. Đối với các nước đang phát triển DNNVV càng có vai trò quan trọng hơn. Đây chính là động lực giúp nền kinh tế phát triển một cách năng động.

\section{THỰC TRẠNG PHÁT TRIỂN CỦA DNNVV TRÊN ĐỊA BÀN THÀNH PHỐ HỒ CHÍ MINH}

Giai đoạn 2006 - 2011, xét theo quy mô lao động bình quân hoặc quy mô vốn bình quân đều thể hiện rằng số lượng DNNVV tăng bình quân khoảng 17\%/năm.

Bảng 3: Số lự̣ng DNNVV trên địa bàn Thành phố Hồ Chí Minh giai đoạn 2006- 2011

Đơn vị tính: doanh nghiệp

\begin{tabular}{|l|c|c|c|c|c|c|}
\hline \multirow{2}{*}{\multicolumn{1}{|c|}{ Chỉ tiêu đánh giá }} & \multicolumn{7}{c|}{ Năm } \\
\cline { 2 - 8 } & $\mathbf{2 0 0 6}$ & $\mathbf{2 0 0 7}$ & $\mathbf{2 0 0 8}$ & $\mathbf{2 0 0 9}$ & $\mathbf{2 0 1 0}$ & $\mathbf{2 0 1 1}$ \\
\hline Phân loại theo quy mô lao động bình quân & 41.860 & 50.007 & 60.881 & 76.083 & 85.161 & 93.053 \\
\hline Phân loại theo quy mô vốn bình quân & 32.211 & 37.596 & 44.633 & 54.327 & 65.758 & 71.852 \\
\hline
\end{tabular}

Nguồn: Tổng cục Thống kê

Số liệu cho thấy, nếu xét theo quy mô lao động bình quân thì số lượng DNNVV trên địa bàn TP.HCM cao hơn nếu xét theo quy mô vốn bình quân. Do đó, để so sánh số lượng doanh nghiệp qua các năm cũng như phân tích tình hình hoạt động kinh doanh ở các phần trình bày sau, nghiên cứu thống nhất sử dụng số liệu phân loại theo quy mô lao động bình quân.

Số lượng DNNVV tăng dần qua các năm trong giai đoạn 2006 - 2009, sau đó tốc độ tăng giảm dần trong hai năm 2010 và 2011. Cụ thể, số lượng DNNVV trên địa bàn thành phố năm 2007 tăng 22,63\% so với năm 2006, năm 2008 tăng 24,63\% so với năm 2007, năm 2009 tăng
27,63\% so với năm 2008; tiếp đó, năm 2010 tăng 11,93\% so với năm 2009, năm 2011 tăng 9,26\% so với năm 2010 (tính toán của tác giả từ số liệu Tổng cục Thống kê). Ngoài ra, theo số liệu của Cục Thuế TP.HCM, năm 2012, tổng số DNNVV trên địa bàn thành phố là 104.316 doanh nghiệp, tăng $17,9 \%$ so với năm 2011, và cao hơn so với giai đoạn 2010 - 2011, thể hiện dấu hiệu phục hồi của nền kinh tế TP.HCM. Các thông tin từ Cục Thuế TP.HCM còn cho thấy hiện các DNNVV chiếm $96,92 \%$ tổng số doanh nghiệp trên địa bàn thành phố năm 2012.

Các lĩnh vực hoạt động chủ yếu của các DNNVV trên địa bàn TP.HCM là bán buôn - bán 
lẻ; xây dựng; công nghiệp chế biến chế tạo; hoạt động khoa học công nghệ; hoạt động hành chính và dịch vụ hỗ trợ; lưu trú và ăn uống; thông tin; kinh doanh bất động sản... Trong đó, ngành bán buôn - bán lẻ chiếm tỷ trọng lớn nhất, với khoảng 40\% tổng số doanh nghiệp (số liệu Cục
Thuế TP.HCM). Như vậy, ta có thể thấy phần lớn các DNNVV tập trung vào các ngành thương mại dịch vụ.

\section{TÌNH HÌNH HOẠT ĐộNG CỦA DNNVV TRÊN ĐỊA BÀN THÀNH PHỐ HỒ CHÍ MINH}

\section{Bảng 4: Một số chỉ tiêu kinh tế của các doanh nghiệp nhỏ và vùa trên địa bàn Thành phố Hồ Chí Minh giai đoạn 2011 - 2012}

Đơn vị tính: tỷ đồng, \%

\begin{tabular}{|c|l|c|c|c|}
\hline Stt & \multicolumn{1}{|c|}{ Chỉ tiêu } & $\begin{array}{c}\mathbf{2 0 1 1} \\
\text { (Tỷ đồng) }\end{array}$ & $\begin{array}{c}\mathbf{2 0 1 2} \\
\text { (Tỷ đồng) }\end{array}$ & $\begin{array}{c}\text { Tốc độ tăng 2012/2011 } \\
\text { (\%) }\end{array}$ \\
\hline 1 & Tổng tài sản & 553.767 & 646.744 & 16,79 \\
\hline 2 & Vốn chủ sở hữu & 258.949 & 307.049 & 18,57 \\
\hline 3 & Tổng doanh thu & 728.034 & 847.461 & 16,40 \\
\hline 4 & Lợi nhuận trước thuế & 16.587 & 15.339 & $-7,52$ \\
\hline 5 & Thuế thu nhập doanh nghiệp & 2.469 & 2.376 & $-3,79$ \\
\hline 6 & Hàng tồn kho & 130.592 & 149.850 & 14,75 \\
\hline 7 & Tỷ lệ nợ trên vốn & 113,59 & 110,21 & $-2,97$ \\
\hline 8 & Tỷ suất sinh lợi trên tài sản & 3,00 & 2,37 & $-20,82$ \\
\hline 9 & Tỷ suất sinh lợi trên vốn chủ sở hữu & 6,41 & 5,00 & $-22,01$ \\
\hline 10 & Tỷ suất lợi nhuận trên doanh thu & 2,28 & 1,81 & $-20,55$ \\
\hline 11 & Số doanh nghiệp thua lỗ & 41.718 & 59.365 & 42,30 \\
\hline 12 & Tổng số lỗ của các doanh nghiệp & 13.146 & 18.065 & 37,42 \\
\hline
\end{tabular}

Nguồn: Tính toán của tác giả tù số liệu do Cục Thuế TP.HCM cung cấp (Số liệu không bao gồm các doanh nghiệp vừa và nhỏ có vốn đầu tu nước ngoài)

Giai đoạn 2011 - 2012, tỷ suất sinh lợi trên tài sản của các DNNVV không cao, và có sụt giảm đáng kể, từ 3,0\% năm 2011 xuống còn 2,37\% năm 2012. Đi sâu phân tích tỷ suất sinh lợi trên tổng tài sản thành tỷ suất sinh lợi trên doanh thu và hiệu suất sử dụng tài sản. Giá trị tỷ suất sinh lợi trên doanh thu cho thấy mức độ kiểm soát tốt chi phí liên quan đến doanh thu của các DNNVV. Trong khi đó, hiệu suất sử dụng tài sản đo lường khả năng trong việc kiểm soát đầu tư trên một mức doanh thu nhất định, thể hiện qua so sánh giữa tốc độ tăng doanh thu và tốc độ tăng tài sản. Số liệu được tính toán cho thấy sự sụt giảm của tỷ suất sinh lợi trên tài sản của các DNNVV là do sự sụt giảm của cả tỷ suất sinh lợi trên doanh thu và hiệu suất sử dụng tài sản. Cụ thể, tỷ suất sinh lợi trên doanh thu giảm 20,55\%, từ 2,28\% năm 2011 xuống còn 1,81\% năm 2012; đồng thời giai đoạn 2011 - 2012, các DNNVV có tốc độ tăng doanh thu $(16,40 \%)$ thấp hơn tốc độ tăng tổng tài sản (16,79\%). Qua đó, ta thấy sự sụt giảm tỷ suất sinh lợi trong tài sản chủ yếu do các DNNVV đã không kiểm soát tốt chi phí liên quan đến doanh thu, còn ảnh hưởng của giảm 
sút trong hiệu suất tài sản không đáng kể. Ngoài ra, khác với tỷ suất sinh lợi trên tổng tài sản, tỷ suất sinh lợi trên vốn cổ phần có xem xét đến chi phí huy động vốn. Tỷ suất sinh lợi trên vốn cổ phần của các DNNVV trên địa bàn thành phố năm 2012 cũng giảm 22,01\% so với năm 2011, từ $6,41 \%$ năm 2011 xuống còn 5,00\% năm 2012.

Từ đó, có thể thấy trong giai đoạn 2011 2012, mặc dù số lượng DNNVV có sự gia tăng cao hơn so với giai đoạn trước; tuy nhiên, hiệu quả kinh tế vẫn còn thấp và chịu nhiều ảnh hưởng của tình hình khó khăn chung, chưa cho thấy nhiều khởi sắc của nền kinh tế. Số DNNVV thua lỗ tăng cao $42,30 \%$, từ 41.718 doanh nghiệp năm 2011 gia tăng lên đến 59.365 doanh nghiệp năm 2012; đồng thời, tổng số lỗ của các DNNVV cũng gia tăng 37,42\%. Trong giai đoạn này, tình trạng hàng tồn kho gia tăng 14,75\%, lợi nhuận trước thuế của các doanh nghiệp sụt giảm 7,52\%, dẫn đến số đóng góp thuế thu nhập doanh nghiệp vào ngân sách nhà nước năm 2012 thấp hơn 3,79\% so với năm 2011. Mặt khác, các DNNVV cũng thận trọng hơn trước các nguồn vốn vay, đòn bẩy tài chính (tỷ lệ nợ trên vốn) năm 2012 giảm 2,79\% so với năm 2011, bởi doanh nghiệp đang gặp khó khăn không đủ năng lực tài chính trả nợ, đồng thời nhu cầu vay thêm để mở rộng hoặc tăng sản lượng sản xuất - kinh doanh của các doanh nghiệp hiện không cao.

\section{NHŨ̉NG THÁCH THỨC ĐẶT RA ĐỐI VỚI DNNVV TRONG GIAI ĐOẠN HIỆN NAY}

DNNVV luôn luôn là giữ vị trí hết sức quan trọng trong nền kinh tế, thể hiện qua việc đóng góp đáng kể tạo ra việc làm, nâng cao thu nhập, thúc đẩy tăng trưởng kinh tế và góp phần xóa đói giảm nghèo. Xuất phát từ đặc điểm bản chât, cũng như thực trạng phát triển của DNNVV, xét trong bối cảnh hội nhập kinh tế, hiện DNNVV phải đối mặt với không ít khó khăn trở ngại trong hoạt động sản xuất kinh doanh. Dưới đây là một trong số những thách thức đó:

- Thách thức do hạn chế về tiềm lục tài chính và khả năng tiếp cận nguồn vốn

Hầu hết các DNNVV bắt đầu phát triển bằng vốn tự có của chủ doanh nghiệp; tuy nhiên, mức ban đầu này rất hạn chế. Khi đã bước đầu thu lợi nhuận và đi vào sản xuất ổn định, DNNVV mong muốn gia tăng vốn để mở rộng đầu tư sản xuất, kinh doanh và phát triển sản phẩm mới. Tuy nhiên, các DNNVV gặp phải nhiều trở ngại trong việc tiếp cận các nguồn vốn; có thể kể đến như giới hạn mức vốn được vay, lãi suất tín dụng cao, khó khăn trong việc duy trì khoản nợ vay và giữ uy tín với ngân hàng. Thực tế cho thấy việc các DNNVV giải thể và phá sản trong thời gian qua chủ yếu do khó khăn về tài chính. Theo số liệu khảo sát của Hiệp hội Doanh nghiệp nhỏ và vừa, mức dư nợ thực hiện đối với các DNNVV chỉ đạt $42,85 \%$ trên tổng mức dư nợ (tính đến cuối tháng 8/2011).

- Thách thức xuất phát tì̀ nguồn lao động

Số lượng việc làm được tạo ra bởi các DNNVV là khá lớn; tuy nhiên, chủ yếu là lao động phổ thông, tỷ lệ lao động qua đào tạo rất thấp. Trình độ đội ngũ nhân sự không cao ảnh hưởng rất lớn đến sự phát triển bền vững của DNNVV. Bởi vì, nếu người lao động có tri thức, tay nghề cao sẽ vận hành tốt các máy móc thiết bị công nghệ tiên tiến, làm ra những sản phẩm tốt về cả chất lượng lẫn mẫu mã, với năng suất và hiệu quả cao. Phần lớn đội ngũ lao động trong các DNNVV hiện nay có trình độ văn hóa cấp II, chiếm khoảng $40-50 \%$; tỷ lệ có trình độ văn hóa phổ thông khoảng 20 - 30\%; còn lại $25-30 \%$ có trình độ tiểu học [1]. Mặt khác, đối với các lao động có năng lực và trình độ cao, DNNVV lại phải đối mặt với khó khăn trong việc giữ chân các đối tượng này. Bởi nhiều hạn chế trong chế độ đãi ngộ và thăng tiến, việc duy trì sự hài lòng người lao động trở thành một trong những thách thức lớn đối với DNNVV. 
- Thách thức do co sở vật chất kỹ thuật, công nghệ lạc hậu, năng suất lao động thấp

Điều kiện thiết bị công nghệ sẽ tác động trực tiếp tối năng suất sản xuất, chất lượng sản phẩm. Tuy nhiên, phần lớn các DNNVV chưa ý thức được đầy đủ về tầm quan trọng của khoa học kỹ thuật trong quá trình cạnh tranh. Vấn đề đổi mới, cải tiến công nghệ để nâng cao năng suất và chất lượng sản phẩm cũng chưa nhận được sự quan tâm đúng mức. Số lượng DNNVV tiếp cận được các chính sách, thông tin hỗ trợ về khoa học - công nghệ còn rất hạn chế. Mặt khác, nếu DNNVV có ứng dụng khoa học - công nghệ, thì hầu hết đây lại là những dây chuyền, máy móc, thiết bị đã lạc hậu, tiêu hao nhiều năng lượng, và thường gây ra nhiều ảnh hưởng tiêu cực đối với môi trường. Theo kết quả khảo sát của Bộ Khoa học và Công nghệ, khoảng $80-90 \%$ thiết bị và công nghệ sử dụng trong các doanh nghiệp của Việt Nam là nhập khẩu và 76\% từ thập niên 1980 - 1990, 75\% máy móc đã hết khấu hao [2]. Các khó khăn về tiềm lực tài chính đã tạo nên nhiều rào cản trong việc đầu tư đổi mới công nghệ tiên tiến, hiện đại ở các DNNVV.

\section{- Thách thức về thị truò̀ng}

Những khó khăn do công nghệ dẫn đến vấn đề chi phí sản xuất cao, chất lượng sản phẩm hạn chế, do đó năng lực cạnh tranh của các DNNVV không cao. Đặc biệt trong bối cảnh kinh tế khó khăn như hiện nay, người dân thắt chặt chi tiêu, các quốc gia giảm sản lượng hàng hóa nhập khẩu. Vì vậy, thị trường tiêu thụ của các DNNVV bị thu hẹp. Song song đó, tình trạng cung vượt quá cầu thường xảy ra trên thị trường do có quá nhiều doanh nghiệp cùng kinh doanh một loại mặt hàng; trong khi đó để chiếm thị phần, DNNVV thường tập trung vào giảm giá hàng hóa - dịch vụ, thay vì cải tiến, đổi mới chất lượng và mẫu mã sản phẩm. Công tác nghiên cứu thị trường của DNNVV chưa được chuyên nghiệp, và thường mang tính chất định tính nhiều hơn định lượng. Ngoài ra, theo nghĩa đầy đủ, thị trường phải bao hàm cả thị trường các yếu tố đầu vào cung ứng nguyên vật liệu, trang thiết bị,... Những khó khăn trong thị trường này cũng cản trở không ít quá trình phát triển của các DNNVV.

- Thách thức do nhũng hạn chế về trình độ quản lý, thiếu cán bộ quản lý có trình độ cao

Bởi tính đơn giản của cấu trúc tổ chức, các chức năng quản trị không được chuyên môn hóa và phân công rõ ràng. Người chủ doanh nghiệp cũng đồng thời nhà người quản lý, nên quyền hạn quản trị gần như tập trung tuyệt đối. Trong khi đó, đối tượng này phần lớn không được đào tạo chuyên môn về quản trị kinh doanh, việc điều hành quản lý chủ yếu dựa trên kinh nghiệm, và thường không xác định chiến lược kinh doanh dài hạn. Nghiên cứu của [1] cho thấy đại đa số chủ doanh nghiệp chỉ có trình độ kiến thức phổ thông (45 - 50\%); một số không nhiều có trình độ văn hóa phổ thông trung học, cao đẳng và đại học (30 - 40\%); còn lại một bộ phận đáng kể có trình độ tiểu học $(10$ - 15\%). Ngoài ra, nghiên cứu này còn cho thấy có rất ít các chủ doanh nghiệp được đào tạo kiến thức quản lý chính quy, một số ít được tập trung đào tạo ngắn hạn (dưới 6 tháng) $(20$ - 30\%), đại đa số chỉ quản lý doanh nghiệp thông qua quá trình thực tiễn. Bên cạnh đó, đối với các DNNVV, văn hóa doanh nghiệp cũng không được chú trọng.

- Thách thức xuất phát tù̀ hạn chế về khả năng tiếp cận thông tin

DNNVV muốn tồn tại và phát triển cần vận hành theo đúng xu thế thị trường. Do đó, đòi hỏi $\mathrm{DN}$ phải nắm bắt tốt được các thông tin về khách hàng, nhu cầu tiêu dùng hiện tại, giá cả, đối thủ cạnh tranh, công nghệ sản xuất mới, các chính sách hỗ trợ từ các cơ quan quản lý nhà nước... Tuy nhiên, DNNVV gặp nhiều khó khăn trong việc tiếp cận và ứng dụng các tri thức mới, do chưa hình thành được bộ phận chuyên trách về thu thập và xử lý thông tin, liên quan đến các hạn chế về tài chính và nhân lực. Hiện hệ thống

\section{Trang 48}


thông tin nước ta mặc dù được phổ biến rộng rãi hơn so với trước đây, với rất nhiều kênh thông tin, nhưng nhìn chung tính chất nhanh chóng, kịp thời, đầy đủ vẫn chưa đáp ứng được những yêu cầu của sản xuất kinh doanh. Đồng thời, DNNVV cũng gặp khó khăn trong việc kiểm chứng độ tin cậy của chúng. Đây cũng là một thách thức đối với DNNVV.

Chung quy, hạn chế lớn nhất của các doanh nghiệp là tri thức và công nghệ. Về tri thức, đấy là hạn chế của chủ doanh nghiệp, các nhà quản lý và hạn chế của người lao động. Điều này dẫn đến những hạn chế về mặt công nghệ: Công nghệ sản xuất và công nghệ quản lý. Những hạn chế này là hạn chế cốt lõi. Vì bản thân các DNNVV là các thực thể có tính thích nghi rất cao, những khó khăn từ bên ngoài hoàn toàn có thể được biến thành những cơ hội. Tuy nhiên, tri thức là yếu tố bên trong, là sức mạnh nội tại quan trọng nhất của các doanh nghiệp vừa và nhỏ. Khi doanh nghiệp không làm chủ được tri thức, họ hoàn toàn có thể phá sản trước các biến động của môi trường kinh doanh. Do vậy, điều cần thiết là phải đánh giá lại khả năng làm chủ tri thức của doanh nghiệp, sự sẵn sàng hấp thụ các tri thức mới của doanh nghiệp nhỏ và vừa. Qua đó, hiểu rõ hơn về khối doanh nghiệp này, khối doanh nghiệp đã và đang là động lực chính để phát triển nên kinh tế.

\section{MộT SỐ KHUYẾN NGHỊ ĐỐI VỚI DNNVV}

Sau khi phân tích về những thực trạng mà DNNVV phải đối mặt trong giai đoạn hiện nay, tác giả xin đề xuất một số giải pháp nhằm hỗ trợ DNNVV nâng cao khả năng cạnh tranh, hướng đến phát triển bền vững, cụ thể như sau:

\section{- Tăng cuòng mở rộng liên kết hợp tác}

Năng lực cạnh tranh sẽ gia tăng sau khi các doanh nghiệp thực hiện liên kết trong sản xuất kinh doanh. Đồng thời, công tác phân công lao động sẽ giải quyết khó khăn về nguồn lực tài chính, do tiết giảm chi phí đầu tư máy móc thiết bị. Chất lượng sản phẩm gia tăng từ kết quả của hoạt động chuyên môn hóa cao. Ngoài ra, việc các doanh nghiệp chia sẻ thông tin, tận dụng mạng lưới phân phối và thế mạnh của nhau để gia tăng thị phần, cũng sẽ giúp các DNNVV đối mặt với các thách thức về thị trường. Mặt khác, cần nâng cao hơn nữa vai trò đặc biệt quan trọng của các hiệp hội ngành nghề, câu lạc bộ doanh nhân trong việc kết nối các doanh nghiệp, giao lưu trao đổi thông tin, hỗ trợ phát triển chuyên môn, đẩy mạnh xúc tiến thương mại trong và ngoài nước.

- Nâng cao trình độ và năng lục nhà quản $l y ́$

Quá trình cạnh tranh khốc liệt trên thị trường đòi hỏi phải tăng cường đào tạo về kiến thức, trình độ quản lý và nghiệp vụ kinh doanh cho chủ doanh nghiệp. Nhà quản lý của các DNNVV phải nỗ lực rèn luyên kỹ năng thu thập, tổng hợp, phân tích, đánh giá các loại thông tin kinh tế trị trường; để đề ra những quyết định và chiến lược đúng đắn kịp thời; cũng như điều hành, giám sát tốt hoạt động của doanh nghiệp.

- Xây dựng và phát triển nguồn nhân lực chất lương cao

DNNVV cần đẩy mạnh công tác đào tạo công nghệ - kỹ thuật tiên tiến và nâng cao tay nghề người lao động. Chất lượng đội ngũ nhân sự gia tăng sẽ đưa đến nhiều thuận lợi trong việc đổi mới quy trình sản xuất, nâng cao chất lượng sản phẩm, cũng như triển khai phát triển sản phẩm mới, nhằm nâng cao năng lực cạnh tranh. Song song đó, chế độ lương thưởng và đãi ngộ đối với nhân tài cần nhận được sự quan tâm đúng mức.

- Hoàn thiện các chính sách hỗ trợ của các co quan quản lý nhà nước

Để giúp các DNNVV duy trì hoạt động kinh doanh và phát triển bền vững, các ngành, các 
cấp chính quyền cần hoàn thiện các hành lang pháp lý, và đề ra các chủ trương, biện pháp hỗ trợ cụ thể. Một số chính sách có thể kể đến như tạo điều kiện cho DNNVV tiếp cận nguồn vốn, hỗ trợ lãi vay, ưu đãi thuế suất,.... Đồng thời, các cơ quan quản lý nhà nước cần đơn giản, quy trình hóa và công khai các thủ tục hỗ trợ này đối với DNNVV.

- Nâng cao khả năng tiếp cận thông tin, tri thức mót của DNNVV

Khả năng tiếp cận thông tin là yếu tố quan trọng để DNNVV nâng cao năng lực cạnh tranh, do đó cần xây dựng và phát triển một hệ thống cung cấp thông tin hoàn thiện. Trong đó, hệ thống này sẽ cung cấp các thông tin cần thiết trong quá trình hoạt động của doanh nghiệp như phương pháp hoạch định chiến lược, ra quyết định đầu tư; thông tin về việc thay đổi hoặc ban hành chính sách và pháp luật liên quan đến môi trường đầu tư, kinh doanh; thông tin về trình tự, thủ tục hành chính, tư pháp; thông tin về những cam kết trong hội nhập kinh tế quốc tế... Ngoài ra, tự bản thân doanh nghiệp phải nỗ lực trong việc hình thành và phát triển bộ phận thu thập và xử lý thông tin chuyên nghiệp.

\section{Kết luận và gọ̣i ý cho nghiên cứu tiếp theo}

DNNVV có những ưu điểm nổi bật mà các loại hình khác không có được, như tính linh hoạt năng động, khả năng thích nghi nhanh chóng với các biến động của thị trường, dễ thay đổi công nghệ, hiệu quả đầu tư tương đối cao, bộ máy quản lý đơn giản, gọn nhẹ. Sự gia tăng mạnh về số lượng DNNVV trong thời gian qua đã minh chứng cho điều đó. DNNVV ngày càng khẳng định vai trò của mình trong phát triển kinh tế. Song song đó, chính bởi các đặc điểm quy mô nhỏ, vốn ít, cấu trúc tổ chức không hoàn chỉnh, thiếu định hướng chiến lược phát triển dài hạn, trình độ đội ngũ lao động thấp, DNNVV đối mặt với không ít thách thức.

Nhằm tạo điều kiện cho các DNNVV phát triển ổn định trong bối cạnh hội nhập kinh tế quốc tế ngày càng sâu rộng như hiện nay, các cơ quan quản lý nhà nước cần triển khai các chính sách, chương trình hỗ trợ, giúp DNNVV vượt qua khó khăn, nâng cao năng lực cạnh tranh, tạo tiền đề cho sự phát triển bền vững. Vai trò cầu nối của các hiệp hội ngành nghề cũng hết sức quan trọng. Tuy nhiên, bên cạnh các biện pháp hỗ trợ từ các đơn vị khác, nỗ lực của DNNVV mới chính là yếu tố quyết định. Bản thân DNNVV phải có sự tự vận động cải tiến, đầu tư khoa học - công nghệ hiện đại, nâng cao năng lực nhà quản lý và trình độ người lao động, gia tăng năng suất lao động và khả năng cạnh trạnh... Đặc biệt, DNNVV cần phải ý thức đúng mức về tầm quan trọng của tri thức, nhằm tiếp cận và ứng dụng tri thức đó vào quá trình sản xuất kinh doanh. Điều đó đồng nghĩa DNNVV phải sẵn sàng trong hấp thụ tri thức mới.

Bài báo được thực hiện trên cơ sở dữ liệu chủ yếu là về các doanh nghiệp nhỏ và vừa trên địa bàn Thành phố Hồ Chí Minh nói chung trong giai đoạn 2006-2012. Mặc dù, với trên 150.000 doanh nghiệp nhỏ và vừa (năm 2013), Thành phố Hồ Chí Minh được xem là địa bàn có nhiều doanh nghiệp vừa và nhỏ nhất của cả nước; tuy nhiên, một nghiên cứu với quy mô mở rộng trên phạm vi cả nước và với các số liệu cập nhật cho năm 2013 và nửa đầu năm 2014 sẽ giúp mang lại cái nhìn toàn diện và cập nhật hơn về chủ đề nghiên cứu. Ngoài ra, các nghiên cứu sâu về từng đối tượng lĩnh vực, ngành nghề quan tâm cũng sẽ giúp mang lại những kết quả chính xác hơn cho từng lĩnh vực, ngành nghề cụ thể. 


\section{TÀI LIỆU THAM KHẢO}

[1]. Bùi Thị Thu Hà (2011), Phát triển doanh nghiệp nhỏ và vùa tại Việt Nam trong bối cảnh hiện nay, Hội thảo khoa học Hội nhập: Hợp tác và cạnh tranh, Trường Đại học Thương mại và trường Cao đẳng Kinh tế Đối ngoại, trang 588 - 598.

[2]. Cao Sỹ Kiêm (2013), Doanh nghiệp nhỏ và vìa: Thưc trang và giải pháp hỗ trợ năm 2013, Tạp chí số 2 năm 2013.

[3]. Tổng cục Thống kê (2009), Thưc trạng doanh nghiệp qua kết quả điều tra, Nhà xuất bản Thống kê, Hà Nội.

[4]. Tổng cục Thống kê (2010), Thưc trạng doanh nghiệp qua kết quả điều tra, Nhà xuất bản Thống kê, Hà Nội.
[5]. Võ Đức Toàn (2012), Tín dụng dối với doanh nghiệp nhỏ và vìa của các ngân hàng thwơng mai cổ phần trên địa bàn thành phố Hồ Chí Minh, Luận án tiến sĩ, Đại học Ngân hàng, thành phố Hồ Chí Minh.

[6]. Võ Phước Tân (2011), Doanh nghiệp nhỏ và vìa với mục tiêu chiến lược cạnh tranh bằng sản phẩm mói, Hội thảo khoa học Hội nhập: Hợp tác và cạnh tranh, Trường Đại học Thương mại và trường Cao đẳng Kinh tế Đối ngoại, trang 245 -255 . 